Tanner (Department of Mechanical Engineering, University of Sydney) gave a paper on non-Newtonian lubricants. Greases and those systems which approximate in their behaviour to Bingham solids give higher bearing friction than Newtonian lubricants. Mr. A. W. Findlay (Monash University, Clayton, Victoria) gave a paper on the rheology of pigment suspensions and outlined a modified Bingham approach to the properties of these systems. Mr. R. Bell (Taubmans Industries, Ltd., St. Peters, N.S.W.) gave a paper on normal stresses in fluids, and stressed the need for emphasis on truly accurately level surfaces. Changing strain velocities can give rise to large normal stresses in many systems, including glycerine and golden syrup.

Dr. H. A. J. Battaerd (Central Research Labora. tory, Imperial Chemical Industries, Australia and
New Zealand, Ltd., Ascot Vale, Victoria) gave an account of a high-speed cinematic record of the performance of an impact tester utilizing a falling sphere which was applied to polythene films. Dr, P. U. A. Grossman (Division of Forest Products, C.S.I.R.O., South Melbourne, Victoria) outlined some unconventional testing methods in the study of creep and vibrational properties of solids.

The Sub-Section held one conjoint meeting with the Pharmaceutical Sciences Section. Two papers were presented, one by Dr. L. Dintenfass on microrheological methods and techniques, and one by Prof. R. C. L. Bosworth on the rheological properties of emulsions. The papers were followed by a panel discussion in which the hosts expressed many ways in which the rheologists could be of help to them.

R. C. L. Bosworth

\title{
THE BRITISH GELATINE AND GLUE RESEARCH ASSOCIATION
}

$\mathrm{T}$ HE twenty-third research panel meeting of the British Gelatine and Glue Research Association was held in London on May 23. The chairman of the Association, Mr. S. G. Hudson (Richard Hodgson and Sons, Beverley), who presided, directed attention to the Association's wide range of interests as reflected in the programme for the day.

The first paper, "The Chemical Nature of Elastin", was contributed by Dr. S. M. Partridge (Low Temperature Research Station, Cambridge). The identification, occurrence, physical properties and isolation of elastin were reviewed. The ease of removal of other proteins from elastin varies with the tissue concerned, but even with the ligamentum nuchae of cattle, autoclaving is necessary. It is recognized that some structural changes are possible during isolation; nevertheless, severo damage is unlikely since there is only $1 \mathrm{~g}$ mole of $N$-terminal residue per $350,000 \mathrm{~g}$ of the isolated protein. The isolated protein is readily broken down into fragments by treatment with acids and the fragments are clearly multichain, indicating the existence of cross-links in the original protein. Enzymatically degraded elastin was chromatographed to give a coloured peptide believed to be the 'core' of the elastin structure. The 'core' gives, on acid hydrolysis, at least four substances of some complexity and these are being examined. The discussion centred round the nature and significance of the 'core'.

In the second paper, Mr. J. A. Mackenzio (R. and P. Schorer, Slough) described "The Manufacture of Gelatine Capsules by the Rotary Die Process". Sheots of plasticized gelatine gel are fed on to a pair of revolving dios and the capsules are automatically filled and sealed on the die. The process calls for a high standard of precision engineering and also for considerable ingenuity in using the unique physical properties of gelatine to the best advantage. Given these factors, capsules of a great variety of shapes and sizes can be made at very high throughput-rates and with a considerable degree of automation.

Dr. R. N. Coleman (Geo. Nelson, Dale, Warwick) gave the third paper, entitled "The Dispersion of Concentrated Gelatine Gels in Hot Syrups". Sometimes high-grade gelatines are encountered which prove to be difficult to disperse in hot, concentrated sugar solutions when using the usual method of soaking the gelatine in water and then adding it as a swollen gel. The difficulty can be minimized by completely dissolving the gelatine in hot water before addition to the syrup: the grist size of the gelatine is important in assisting easy solution in this mothod. Even so, a fow gelatines remain which cannot be dispersed unless the amount of water in the system is increased.

The final paper, "The Cross-linking of Glues with Epoxy Compounds and Formaldehyde Donors", by J. A. Gibbs, I. R. Whiteside and J. Wootton (British Gelatine and Glue Research Association), was presented by Mr. I. R. Whiteside. There has been a general desire to get away from formaldehyde as a cross-linking agent for animal glues because it is toxic and unpleasant to handle. There is a need also for cross-linking agents which can be mixed with glue to give compositions of reasonable pot-life and which can be cured to insolubility after application. It was shown that these requirements could be met by using either dimethylol urea as a donor of formaldehyde in solution or an epoxy resin.

D. A. SuTroN

\section{EDUCATION OF TECHNICIANS AND TECHNOLOGISTS}

\begin{abstract}
$\mathrm{A}^{\mathrm{N}}$ $\mathrm{N}$ international conference on this topic was held in Cracow, Poland, during September 6-10,1961, to discuss the education and further training of technical personnel.

The conference was initiated by the Association of Engineers of the General Technical Federation of Poland (Scientific World, 6, No. 1; 1962). The
\end{abstract}

Associations of Engineers and Ministries of Higher Education of Czechoslovakia, the German Democratic Republio, Yugoslavia, Poland, Hungary and the Soviet Union also took part in the organization of the conference. Representatives of the Prague Regional Centre of the World Federation of Scientific Workers and of the Higher Schools and Scientific Institutes 